\title{
Decarbonylative Cross Coupling of Phthalimides with Diorganozinc Reagents-Efforts Toward Catalysis
}

\author{
Kimberly S. DeGlopper, Sarah K. Fodor, Thomas B. D. Endean, and \\ Jeffrey B. Johnson ${ }^{*}$ \\ Department of Chemistry, Hope College, Holland, MI 49423 USA
}

jjohnson@hope.edu

\section{Graphical Abstract}

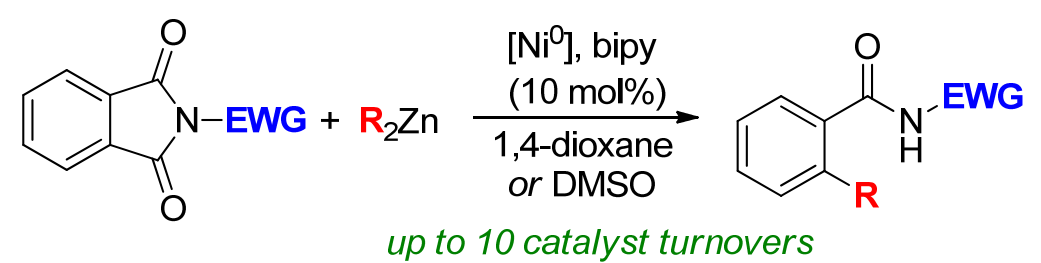

The catalytic decarbonylative coupling of phthalimides with diorganozinc reagents has been demonstrated utilizing $\mathrm{Ni}(0)$ catalysts. The use of electron deficient nitrogen substitution results in efficient formation of $o$-substituted benzamides with up to 10 catalyst turnovers.

\begin{abstract}
The decarbonylative coupling of phthalimides with diorganozinc reagents to form $o$-substituted benzamides has been previously demonstrated as a viable process, but only with stoichiometric nickel(0). Investigations into a number of reaction variables, including solvent, ligand, and substrate substitution, have yielded multiple sets of conditions capable of achieving up to 10 catalyst turnovers, most successfully with the use of electron withdrawing nitrogen substituents on the phthalimide. In addition, these investigations have provided insight into the intermediates within the catalytic cycle and have revealed new approaches to the development of a general catalytic methodology.
\end{abstract}

Keywords: decarbonylation, alkylation, catalysis, imide, diorganozinc reagents

\section{Introduction}


The use of transition metals to accomplish the cross coupling methodologies has fundamentally changed the avenues through which complex molecules are synthesized [1]. The expansion of viable nucleophilic and electrophilic coupling partners continues at a rapid pace, incorporating all manners of functional groups, many of which are incorporated into these reactions with high levels of chemo-, regio- and stereoselectivity [2]. In some cases the functional groups within coupling partners may be challenging to prepare or handle, and thus can be more readily approached through the controlled modification of more stable starting materials. In this vein, decarboxylative coupling methods using carboxylic acids $[3,4]$ or esters [5,6] as the source of alkyl nucleophiles has been well known for many years, as has the decarbonylation of carbonylcontaining functionalities, first reported using aldehydes in 1965 by Tsuji and coworkers [7]. Beyond aldehydes [8], subsequent decarbonylative cross-coupling reactions have been performed with carboxylic acids[9], esters [10], carboxylic anhydrides [11], ketones [12] and imides [13].

In a recent paper, our group described the development of a nickel(0)-mediated transformation for the decarbonylative cross-coupling of phthalimides with diorganozinc reagents to generate $o$ substituted benzamides in high yields (Scheme 1) [14]. This methodology is tolerant of a wide range of imide substitution, including alkyl, aryl and heteroatom substitution off of the nitrogen. Notably, the methodology also proceeds efficiently with a broad range of diorganozinc reagents, including those prepared from aryl halides via lithium-halogen exchange and utilized without purification.

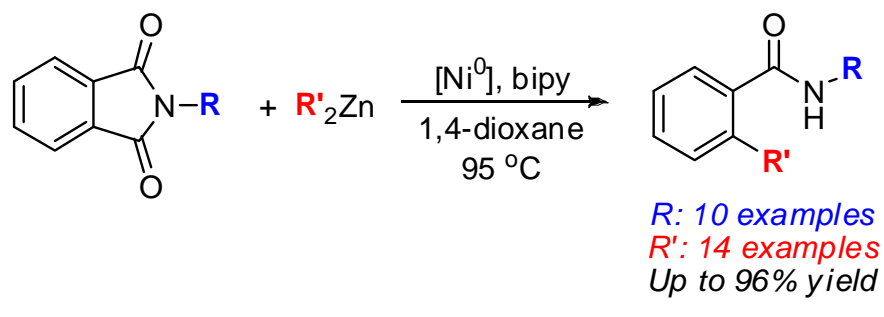

\section{SCHEME 1.}

Despite the success in the aforementioned development of the decarbonylative cross-coupling of imides and diorganozinc reagents, the methodology has significant drawbacks, perhaps most notably the requirement of stoichiometric nickel to achieve the transformation. As such, significant efforts were undertaken to achieve catalysis. Initial efforts largely focused upon the screening of a range of reaction conditions, including variation of solvent, ligand, and imide substituent among other factors, while more recent efforts have had a more mechanistic focus. In all, these combined efforts have led to an increase in the synthetic utility of the reaction with the achievement of modest catalysis but have also provided mechanistic insight into the nature of the decarbonylative transformation. 


\section{Experimental}

General Methods. All reactions were carried out under an atmosphere of nitrogen or argon in oven dried glassware with magnetic stirring. Solvents, including DMSO, DMF, toluene, tetrahydrofuran, and diethyl ether were purged with argon and passed through two columns of neutral alumina or molecular sieves. Diethylzinc, most ligands, and nickel precatalysts are commercially available and used without purification or prepared according to procedures provided. All phthalimides were obtained commercially or prepared via the condensation of phthalic acid with the appropriate amine in either refluxing toluene (Dean-Stark conditions) or in refluxing acetic acid [15].

General Method for Catalytic Decarbonylative Coupling with $\mathbf{E t}_{2} \mathbf{Z n}$ will be illustrated with a specific example. 2,2'-Bipyridine (bipy) (15.6 mg, $0.010 \mathrm{mmol}$ ) and $N$-phenylphthalimide (1) (238 mg, $0.90 \mathrm{mmol}$ ) were combined in an oven dried $25 \mathrm{~mL}$ round bottom flask and transferred into an inert atmosphere glove box, where $\mathrm{Ni}(\mathrm{COD})_{2}(\mathrm{COD}=1,5$-cyclooctadiene $)$ (24.8 $\mathrm{mg}$, $0.090 \mathrm{mmol}$ ) was added. The flask was sealed with a septum and removed from the glove box. DMSO $(2.5 \mathrm{~mL})$ was added via syringe, followed by $\mathrm{Et}_{2} \mathrm{Zn}(70 \mu \mathrm{L}, 0.67 \mathrm{mmol})$ also via syringe. The dark solution was then suspended in a $100{ }^{\circ} \mathrm{C}$ oil bath and allowed to stir for $16 \mathrm{~h}$.

Following reaction, the reaction was cooled to room temperature, the septum was removed and the reaction mixture was diluted with $\mathrm{Et}_{2} \mathrm{O}(15 \mathrm{~mL})$. The addition of $2 \mathrm{M}$ aq $\mathrm{HCl}(15 \mathrm{~mL})$ quenched the reaction, which was then extracted with $\mathrm{Et}_{2} \mathrm{O}(3 \times 15 \mathrm{~mL})$. The combined organic layers were washed with brine $(15 \mathrm{~mL})$, dried over $\mathrm{MgSO}_{4}$ and concentrated under reduced pressure to yield crude 2-ethyl- $N$-phenylbenzamide (2).

Purification and Analysis. Products of the above procedure were analyzed via GC/MS (Agilent 6890 GC with Agilent 5973 mass selective detector), IR (Bruker Alpha, diamond ATR), and NMR spectroscopy (Bruker $400 \mathrm{MHz}$ Avance III). ${ }^{1} \mathrm{H}$ and ${ }^{13} \mathrm{C}$ NMR spectra were acquired using standard acquisition parameters and are referenced to TMS. Purification was achieved through column chromatography (10:1 hexane:ethyl acetate) and thoroughly characterized.

The General Method for In situ IR spectroscopy for investigation of the reaction progress will be illustrated with a specific example. A $10-\mathrm{mL}$ flask was sealed with a septum and placed under argon atmosphere. 1,4-dioxane $(2 \mathrm{~mL})$ was added to the flask via syringe. The solvent was heated in a $95^{\circ} \mathrm{C}$ oil bath. $N$-Pentafluorophenylphthalimide (3) (157 mg, $\left.0.050 \mathrm{mmol}\right)$ and 2,2'bipyridine $(8.6 \mathrm{mg}, 0.055 \mathrm{mmol})$ were weighed out into an oven-dried, two-necked 10-mL flask with a stir bar and transferred into an inert atmosphere glovebox, where $\mathrm{Ni}(\mathrm{COD})_{2}$ was added to the flask, and the flask was sealed with a septum. While utilizing a flow of argon from a balloon to preserve the inert atmosphere, in situ IR probe was inserted into one of the necks of the twonecked flask. The flask was then flushed with argon $(5 \times)$. Next, 1,4-dioxane was transferred from the $10-\mathrm{mL}$ flask to the two-necked flask via syringe. The two-necked flask was immersed in a $95{ }^{\circ} \mathrm{C}$ oil bath. A background spectrum was acquired. For the next 10-15 min, a spectrum 
was taken every one minute. Finally, diethyl zinc $(70 \mu \mathrm{L}, 0.67 \mathrm{mmol})$ was added to the flask via syringe. For the remainder of the reaction (1-3 hours), a spectrum was taken every minute.

\section{Results and Discussion}

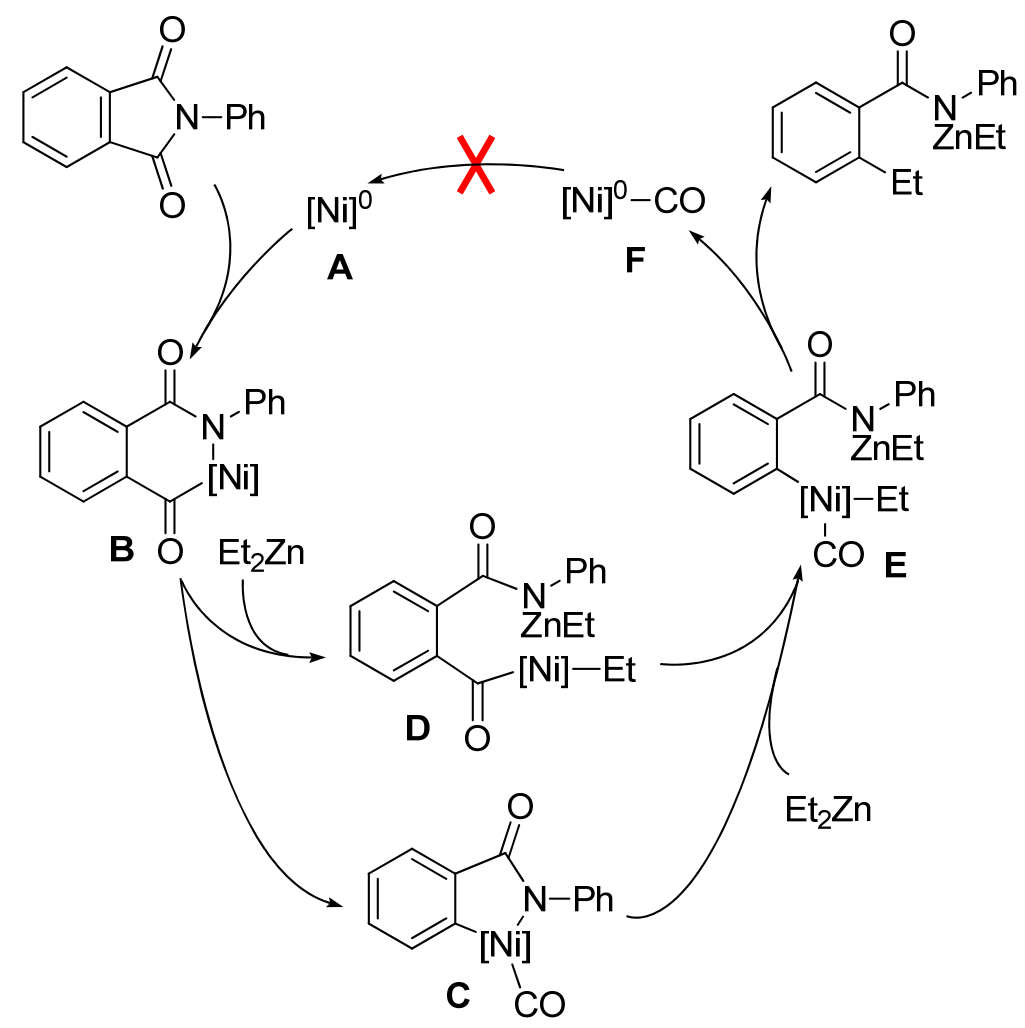

SCHEME 2. Mechanistic hypothesis

As presented in our initial report, our mechanistic hypothesis for the decarbonylation reaction is illustrated in Scheme 2. The active nickel(0) complex A undergoes a formal oxidative addition into the phthalimide to generate metalacycle $\mathbf{B}$. This species undergoes transmetallation with $\mathrm{Et}_{2} \mathrm{Zn}$ to generate $\mathbf{D}$ and subsequent decarbonylation to provide complex E. Reductive elimination and acid workup yields the ortho-substituted benzamide and regenerates nickel (0) complex F. In a potential alternative, metalacycle $\mathbf{B}$ may undergo decarbonylation prior to transmetallation which would generate complex $\mathbf{C}$ before proceeding to $\mathbf{E}$. Independent of the specific pathway, it is hypothesized that the strength of the Ni-CO bond in the final nickel(0) species $\mathbf{F}$ prevents dissociation, and the complex is not sufficiently nucleophilic to induce oxidative addition to achieve catalysis $[16,17,18]$. These factors contribute to the requirement for stoichiometric nickel to mediate the transformation.

In analyzing reaction conditions, we identified several means of altering reaction conditions that had the potential to invoke catalyst turnover, including changing the ligand, solvent and substitution on the imide, with the initial intent of weakening the final Ni-CO bond to induce dissociation and achieve the regeneration of a catalytically active nickel species. 
Standard reaction conditions for the stoichiometric decarbonylative coupling included the use of 1 equiv $\mathrm{Ni}(\mathrm{COD})_{2}, 1.1$ equiv bipy (2,2'-bipyridyl) and 1.2 equiv Et $2 \mathrm{Zn}$ in 1,4-dioxane at $95^{\circ} \mathrm{C}$ for 16 hours. The reaction can also be performed utilizing a $\mathrm{Ni}(\mathrm{II})$ precursor such as $\mathrm{Ni}(\mathrm{acac})_{2}$ $(\mathrm{acac}=$ acetylacetonate); however this requires additional diorganozinc reagent to reduce the metal center to a catalytically active $\mathrm{Ni}(0)$ species. In an early attempt at catalysis, $\mathrm{N}$-phenyl phthalimide was combined with $20 \mathrm{~mol} \% \mathrm{Ni}(\mathrm{COD})_{2}$ and $21 \mathrm{~mol} \%$ bipy under otherwise identical conditions, yielding $19 \%$ of the anticipated benzamide coupling product, consistent with the optimized stoichiometric reaction.

Characteristics of the reaction solvent clearly influence catalytic turnover. The initially developed reaction conditions utilized 1,4-dioxane heated at $95^{\circ} \mathrm{C}$ in an oil bath. Using $10 \mathrm{~mol} \%$ of catalyst, a significant range of solvents were examined, with significant variability in polarity, boiling point and tendency to coordinate to transition metals. These solvents were tested under otherwise identical reaction conditions at temperatures near their boiling points. High boiling solvents generally resulted in greater catalyst turnover as did solvents with a strong ability to coordinate a metal center. Based on our current mechanistic hypothesis, it is believed that solvent molecule coordination assists in the dissociation of carbon monoxide from the metal center to regenerate nickel(0) species A (Scheme 1), thus achieving catalyst turnover. While DMF was quite promising, these reactions were plagued by side reactions of the diorganozinc reagents with the DMF leading to inseparable byproducts. Likewise, reactions performed in 1,2-dichloroethane and toluene led to a significant amount of substrate conversion to undesired species. Thus DMSO and 1,4-dioxane were generally pursued for reactivity.

TABLE 1. Effects of solvent on the catalytic decarbonylative coupling.

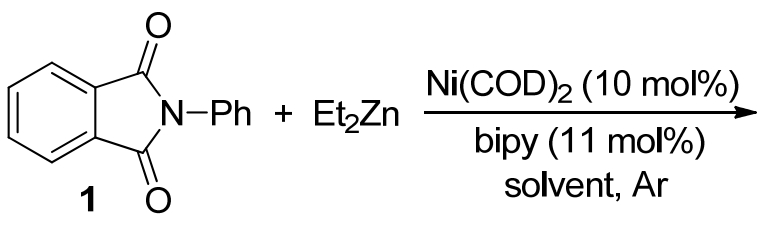

\begin{tabular}{ll}
\hline Entry $^{a}$ & Solvent \\
\hline 1 & 1,4-dioxane
\end{tabular}

THF

Toluene

DMSO

$\mathrm{CH}_{2} \mathrm{Cl}_{2}$

$\mathrm{MeCN}$<smiles>CCc1ccccc1C(=O)Nc1ccccc1</smiles>

10

8

13

19

$<5$

$<5$ 
a) Reaction conditions: $N$-Phenylphthalimide ( $0.9 \mathrm{mmol}, 1.0$ equiv), $\mathrm{Ni}(\mathrm{COD})_{2}(10 \mathrm{~mol} \%)$, bipyridine (11 mol\%), Et $2 \mathrm{Zn}$ (1.1 equiv), in $2.5 \mathrm{~mL}$ of solvent under an atmosphere of $\mathrm{Ar}$, heated in an oil bath within $5{ }^{\circ} \mathrm{C}$ of solvent boiling point. b) Determined by GC analysis.

A significant series of ligands was also examined for reactivity. The stoichiometric reaction conditions utilized bipy as the ligand - it was initially hypothesized that the use of more $\pi$ accepting ligands would assist in weakening the $\mathrm{Ni}-\mathrm{CO}$ bond, leading to the dissociation of carbon monoxide and catalyst turnover. While ligand examination included a number of $\pi$ accepting species, a broad range of nitrogen and phosphorous based mono- and bidentate ligands were examined for reactivity (Table 2).[19] Unfortunately, no obvious trends were observed. The $\pi$-accepting analogue of bipy, 4,4'-diazafluoren-9-one [20], showed no improved over the use of bipy itself (entries 3 and 4.) The majority of reactions led to little or no turnover and little difference using either DMSO or 1,4-dioxane as the solvent. The influence of ligands on the reaction pathway was quite obvious with the series of monodentate phosphines examined for reactivity (entries 13-18). Despite not providing the desired decarbonylation product, these ligands provided significant amounts of the 3-substituted-3-hydroxy-gamma-lactone, the product of nickel-catalyzed addition of the diorganozinc ligand directly to the imide carbonyl without decarbonylation. With the use of triphenylphosphine, the direct addition product was provided in nearly quantitative yield in the presence of only $10 \mathrm{~mol} \%$ of the nickel catalyst (Scheme 3).[21] Unfortunately, no combination of ligand and solvent examined increased the reaction yield above $22 \%$, with 2,2 '-bypyridine remaining the most economical choice for continued reaction exploration.

TABLE 2. Effects of ligand on the catalytic decarbonylative coupling.

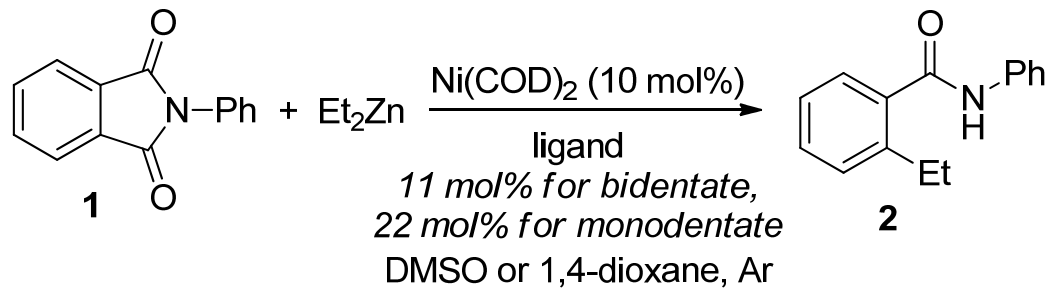

\begin{tabular}{llll}
\hline Entry $^{a}$ & Ligand & Solvent & Yield (\%) $^{b, c}$ \\
\hline 1 & $2,2^{\prime}$-bipyridine & DMSO & 19 \\
2 & $2,2^{\prime}$-bipyridine & 1,4 -dioxane & 10 \\
3 & $4,4^{\prime}$-diazafluoren-9-one & DMSO & 11
\end{tabular}




\begin{tabular}{|c|c|c|c|}
\hline 4 & 4,4'-diazafluoren-9-one & 1,4-dioxane & 8 \\
\hline 5 & 1,10-phenanthroline & DMSO & $<5$ \\
\hline 6 & 1,10-phenanthroline & 1,4-dioxane & $<5$ \\
\hline 7 & bathocuproine & DMSO & 6 \\
\hline 8 & bathocuproine & 1,4-dioxane & 9 \\
\hline 9 & neocuproine & DMSO & $<5$ \\
\hline 10 & neocuproine & 1,4-dioxane & $<5$ \\
\hline 11 & 2-[2-(diphenylphosphino)ethyl]pyiridine (pyphos) & DMSO & $12(20)$ \\
\hline 12 & 2-[2-(diphenylphosphino)ethyl]pyiridine (pyphos) & 1,4-dioxane & 9 \\
\hline 13 & $\mathrm{PCy}_{3}$ & DMSO & 4 \\
\hline 14 & $\mathrm{PCy}_{3}$ & 1,4-dioxane & $22(55)$ \\
\hline 15 & $\mathrm{PPh}_{3}$ & DMSO & 10 \\
\hline 16 & $\mathrm{PPh}_{3}$ & 1,4-dioxane & $<5(60)$ \\
\hline 17 & $\mathrm{PMe}_{3}$ & DMSO & 8 \\
\hline 18 & $\mathrm{PMe}_{3}$ & 1,4-dioxane & $<5(48)$ \\
\hline 19 & 1,3-bis(diphenylphosphino)propane (dppp) & DMSO & 12 \\
\hline 20 & 1,3-bis(diphenylphosphino)propane (dppp) & 1,4-dioxane & 4 \\
\hline
\end{tabular}

a) Reaction conditions: $N$-Phenylphthalimide ( $0.9 \mathrm{mmol}, 1.0$ equiv), $\mathrm{Ni}(\mathrm{COD})_{2}(10 \mathrm{~mol} \%)$, ligand (11 mol\% for bidentate, $22 \mathrm{~mol} \%$ for monodentate), Et $2 \mathrm{Zn}$ (1.1 equiv), in $2.5 \mathrm{~mL}$ of solvent under an atmosphere of Ar, heated in an oil bath within $5{ }^{\circ} \mathrm{C}$ of solvent boiling point. b) Determined by GC analysis. c) Value in parenthesis corresponds to the amount of direct addition 3-hydroxy-gamma-lactone product observed.

SCHEME 3. The direct addition product observed in the presence of monodentate phosphine ligands. 


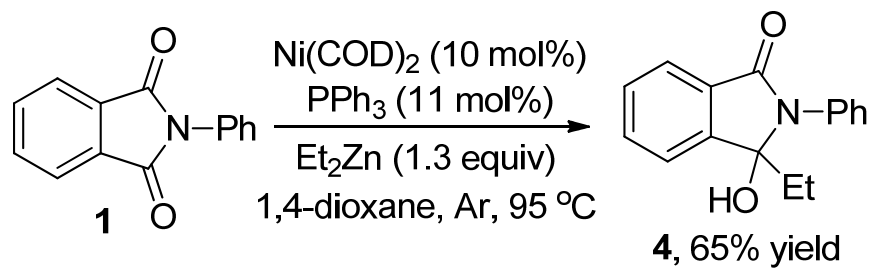

In early efforts of exploring catalysis, it was observed that the inclusion of electron withdrawing substituents on the nitrogen of the phthalimide had an impact on catalyst turnover. While use of $\mathrm{N}$-phenylphthalimide and $\mathrm{Et}_{2} \mathrm{Zn}$ with $10 \mathrm{~mol} \% \mathrm{Ni}(\mathrm{COD})_{2}$ and bipy showed little catalyst turnover, even in DMSO at $100{ }^{\circ} \mathrm{C}$, use of the perfluorinated $\mathrm{N}_{-} \mathrm{C}_{6} \mathrm{~F}_{5}$ phthalimide provided the corresponding decarbonylative coupling product in $50 \%$ yield (Table 3 ). Imides with nitrogenaryl substitution containing various fluorine substitution, trifluoromethyl groups, and esters reacted in a similar fashion, with all groups containing electron deficient substitution providing catalyst turnover. In contrast, $N$-phenylphthalimides and related imides containing electron donating substitution on the aryl ring resulted in little or no catalyst turnover.

TABLE 3. Effects of phthalimide substitution on the catalytic decarbonylative coupling.

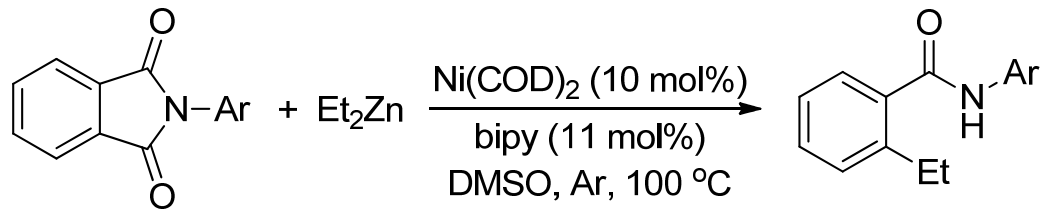

\begin{tabular}{llll}
\hline Entry $^{a}$ & $\mathrm{Ar}$ & Product & Yield (\%) \\
\hline 1 & $o-\mathrm{F}-\mathrm{C}_{6} \mathrm{H}_{4}$ & $\mathbf{5}$ & $65^{c}$ \\
2 & $2,6-\mathrm{F}_{2}-\mathrm{C}_{6} \mathrm{H}_{3}$ & $\mathbf{6}$ & $61^{d}$ \\
3 & $3,5-\left(\mathrm{CF}_{3}\right)_{2}-\mathrm{C}_{6} \mathrm{H}_{3}$ & 7 & 53 \\
4 & $2,3,4,5,6-\mathrm{F}_{5} \mathrm{C}_{6}$ & $\mathbf{8}$ & 51 \\
5 & $4-\mathrm{CO}_{2} \mathrm{Et}_{-} \mathrm{C}_{6} \mathrm{H}_{5}$ & $\mathbf{9}$ & 64 \\
6 & $N-$ pyrrole $_{7}$ & $\mathbf{1 0}$ & $52^{e}$ \\
7 & $\mathrm{Ph}$ & $\mathbf{2}$ & 19 \\
8 & $4-\mathrm{OCH}_{3}-\mathrm{C}_{6} \mathrm{H}_{5}$ & $\mathbf{1 1}$ & $14^{d}$ \\
9 & $4-\mathrm{N}\left(\mathrm{CH}_{3}\right)_{2}-\mathrm{C}_{6} \mathrm{H}_{5}$ & $\mathbf{1 2}$ & $12^{d}$
\end{tabular}

a) Reaction conditions: $N$-Arylphthalimide ( $0.9 \mathrm{mmol}, 1.0$ equiv), $\mathrm{Ni}(\mathrm{COD})_{2}(10 \mathrm{~mol} \%)$, bipy (11 mol\%), Et $2 \mathrm{Zn}$ (1.1 equiv), in $2.5 \mathrm{~mL}$ of DMSO at $100^{\circ} \mathrm{C}$ under an atmosphere of Ar. b) 
isolated yield, except as noted. c) 20 mol\% catalyst loading. d) Determined by GC analysis. e) Also obtained $45 \%$ of gamma-hydroxy lactone direct addition product.

Following the trend of increasing electron deficient substitution, the $N$-tosyl substituted imide was also examined for reactivity. Much to our delight, we obtained nearly full conversion of the starting material to the desired decarbonylated coupling product, even with only $10 \mathrm{~mol} \%$ of $\mathrm{Ni}(\mathrm{COD})_{2}$ and bipy. A series of additional experiments revealed that by using 1.5 equivalents of $\mathrm{Et}_{2} \mathrm{Zn}$, the reaction was also successful with $10 \mathrm{~mol} \%$ of $\mathrm{Ni}(\mathrm{acac})_{2}$ as the precatalyst, alleviating the need for an air sensitive catalyst precursor and providing the alkylated product in over $85 \%$ yield (Scheme 4). The reaction proceeded with similar efficiency down to $1 \%$ catalyst loading, but no product was observed in the absence of a nickel catalyst. For the solvent, 1,4-dioxane was used instead of DMSO. The reaction was also highly successful using di- $n$-butyl zinc generated from the reaction of $n \mathrm{BuLi}$ and $\mathrm{ZnCl}_{2}$ and used without purification. Despite the promising start, all efforts to expand the scope of diorganozinc reagents to diaryl zinc species were unsuccessful, simply providing unreacted starting material in all cases.

\section{SCHEME 4.}

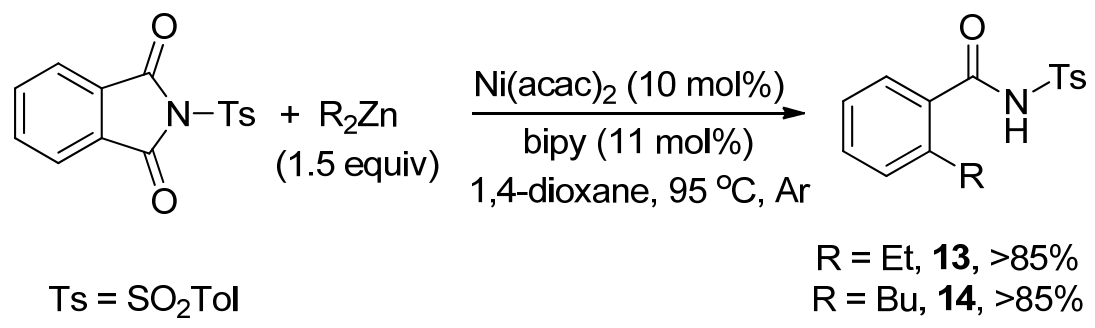

Along a similar line, $N$-hydroxy and $N$-methoxy substituted phthalimides were examined for reactivity with $10 \mathrm{~mol} \% \mathrm{Ni}(\mathrm{acac})_{2}$ and $\mathrm{Et}_{2} \mathrm{Zn}$ in 1,4-dioxane. These substrates are amenable to reaction, efficiently undergoing the desired decarbonylative coupling. Surprisingly, the nitrogenoxygen bond is cleaved in the process, yielding the reduced $o$-ethylbenzamide in greater than $80 \%$ yield from both substrates (Scheme 5). Much like the previously described reactions with $\mathrm{N}$-tosyl phthalimides, however, reactions of this type are limited to dialkylzinc reagents.

\section{SCHEME 5.}

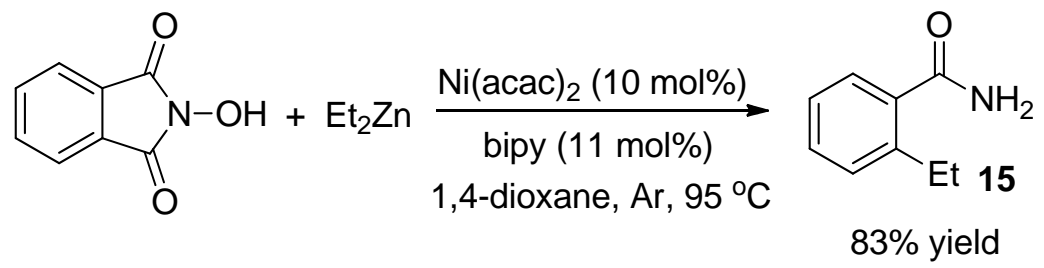


The significant influence of the nitrogen substitution on catalytic turnover is notable, as initial mechanistic hypotheses assumed the nitrogen to have dissociated from the metal center prior to potential dissociation of carbon monoxide. Instead, it appears that in order to achieve catalytic turnover, carbon monoxide dissociates from an earlier intermediate, one in which the nitrogen of the phthalimide is still coordinated to the nickel. In theory, intermediates $\mathbf{C}$ and/or $\mathbf{D}$ (Scheme 2) are likely intermediates from which carbon monoxide could dissociate. Furthermore, these putative intermediates are both in the $\mathrm{Ni}$ (II) oxidation state, which is expected to bind more weakly to the pi-accepting $\mathrm{CO}$ ligand than the $\mathrm{Ni}(0)$ species formed upon completion of the reaction.

To further probe the influence of the imide substrate and the dissociation of carbon monoxide, the reactivity of $o$-fluorinated $N$-phenylphthalimide was examined (Scheme 6). Based upon a number of computational studies as well as experimental evidence from a palladium system examined in our laboratory [22], the presence of an $o$-fluorine substituent has the capability of stabilizing a metal-aryl complex by up to $11 \mathrm{kcal} / \mathrm{mol}$ [23]. Applying such a strategy to this system, we anticipate that $\mathrm{Ni}(\mathrm{II})$ intermediates $\mathbf{C}$ or $\mathbf{E}$ (Scheme 2), regardless of the specific path formed, would be stabilized by the presence of an ortho-fluorine. The subsequent longer lifetime of this intermediate would allow time for dissociation of carbon monoxide, and ultimately result in catalyst turnover. Upon subjection to $10 \mathrm{~mol} \% \mathrm{Ni}(\mathrm{COD}) 2,11 \mathrm{~mol} \%$ bipy, and 1.5 equiv Et $2 \mathrm{Zn}$ in 1,4-dioxane at $95{ }^{\circ} \mathrm{C}, 52 \%$ of product was obtained - an increase from $10 \%$ obtained with the unfluorinated species. Based upon NMR and GC/MS analysis, it appears that the product is formed as a single regioisomer, the assignment of which is based upon results obtained when utilizing 3-methyl substituted $\mathrm{N}$-phenylphthalimide, for which the product regiochemistry was confirmed by nOe experiments. (See Supporting Information for details.) The observation of catalysis and regioselectivity, coupled with our results from varying the nitrogen substitution, lends credence to the hypothesis that carbon monoxide dissociation precedes transmetallation with the diorganozinc reagent, and that successful catalysis is achieved primarily through dissociation of carbon monoxide from a Ni(II) intermediate such as $\mathbf{G}$ or $\mathbf{H}$ (Scheme 6).

\section{SCHEME 6.}<smiles>CCc1c(F)cccc1C(=O)Nc1ccccc1</smiles><smiles>CCN(C(=O)c1cccc(F)c1[N+](C=O)(CC)Nc1ccccc1)c1ccccc1</smiles> 
To gain additional insight into the mechanism of reaction, we also probed the stoichiometric reaction of $N$-pentafluorophenylphthalimide with $\mathrm{Et}_{2} \mathrm{Zn}$ mediated by $\mathrm{Ni}(\mathrm{COD})_{2}$ and bipy in 1,4dioxane utilizing in situ IR spectroscopy. After obtaining background spectra of each component, we sequentially added each reagent and monitored the change, both at room temperature and at $95^{\circ} \mathrm{C}$, the typical reaction temperature. Upon the addition of each subsequent reagent, peaks were observed to shift and change in intensity but not completely disappear, suggesting that several species are most likely within equilibrium throughout the reaction progress. Following the addition of the final reagent, Et $2 \mathrm{Zn}$, a strong IR absorbance at $1906 \mathrm{~cm}^{-1}$ appears almost instantaneously upon immersion in a $95^{\circ} \mathrm{C}$ oil bath. This absorbance diminishes slowly with approximate zero-order kinetics for the first half life over the course of approximately 3 hours (Figure 1). As confirmed by experiments in which the reaction is quenched at various time points, the disappearance of the absorbance at $1906 \mathrm{~cm}^{-1}$ correlates to the formation of the desired decarbonylative coupling product [24]. As the species with the IR absorbance is not observed prior to addition of diethylzinc, this intermediate is tentatively assigned as the nickel(II) aryl alkyl carbonyl intermediate, species $\mathbf{E}$ in Scheme 1. Efforts to isolate this intermediate and other potential reaction intermediates are underway, as is a more detailed kinetic analysis of the decarbonylative coupling process.

FIGURE 1. Appearance and decay of $\mathrm{C}=\mathrm{O}$ stretch at $1906 \mathrm{~cm}^{-1}$ during the decarbonylative coupling of phthalimide 3 .<smiles>CCc1ccccc1C(=O)Nc1c(F)c(F)c(F)c(F)c1F</smiles> 


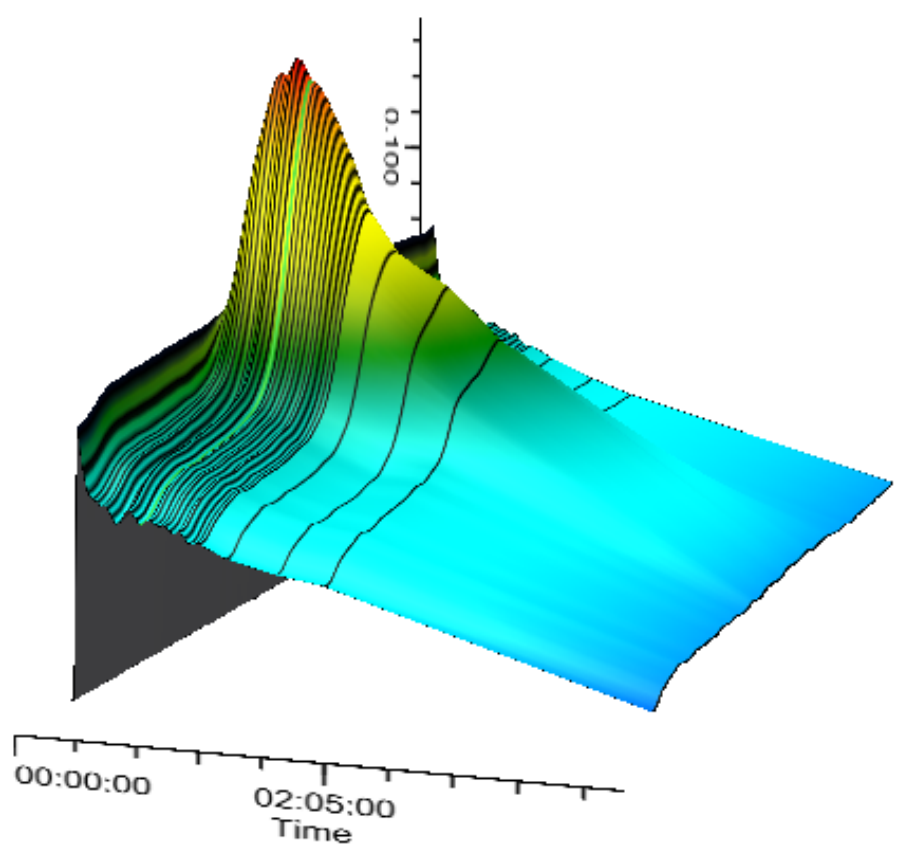

\section{Conclusion}

In summary, a series of experiments have explored potential reaction conditions and provided insight into the mechanistic underpinnings of the nickel(0)-catalyzed decarbonylative coupling of phthalimides with diorganozinc reagents. These efforts have yielded conditions capable of achieving modest catalytic turnover under a number of specific conditions, with electron deficient presumably via weakening the Ni-CO bond in a Ni(II) intermediate. In particular, $\mathrm{N}$ tosyl substituted phthalimides are particularly amenable to catalytic decarbonylative coupling, achieving nearly quantitative yields. The results of these efforts have been combined with a rudimentary mechanistic investigation to reveal intermediates on the reaction pathway that are potential targets for the development of a truly general catalytic decarbonylative coupling methodology.

\section{Acknowledgements}

Acknowledgment is made to the Schaap Research Fellows Program (J.B.J.), the National Science Foundation (CHE-1148719), and the Camille and Henry Dreyfus Foundation (TH-15-030) for financial support of this research. K.S.D. thanks the Dow Scholars Program, funded by the Herbert H. and Grace A. Dow Foundation. Grants from the National Science Foundation for the purchase of NMR spectrometers (CHE-0922623) and GC/MS instrumentation (CHE-0952768) are also gratefully acknowledged.

\section{Appendix A. Supplementary Material}




\section{References}

[1] de Meijere, A.; Diederich, F. Metal-catalyzed Cross-Coupling Reactions, 2nd Edition; Wiley-VCH: Weinheim, 2004.

[2] Johansson Seechurn, C. C. C.; Kitching, M. O.; Colacot, T. J.; Snieckus, V. Angew. Chem. Int. Ed.2012, 51, 5062 .

[3] For a review, see Goossen, L. J.; Rodríguez, H.; Goossen, K. Angew. Chem. Int. Ed. 2008, 47, 3100.

[4] a) Goossen, L. J.; Deng, G.; Levy, L. M. Science 2006, 313, 662. b) Baudoin, O. Angew. Chem. Int. Ed. 2007, 46, 1373 and references therein. c) Zhang, F.; Greaney, M. F. Org. Lett. 2010, 12, 4745. d) Goossen, L. J.;

Rodriguez, N.; Lange, P.; Linder, C. Angew. Chem. Int. Ed. 2010, 49, 1111.

[5] Mohr, J. T.; Nishimata, T.; Behenna, D. C.; Stoltz, B. M. J. Am. Chem. Soc. 2006, 128, 11348.

[6] Trost, B. M.; Xu, J.; Schmidt, T. J. Am. Chem. Soc. 2009, 131, 18343.

[7] Tsuji, J.; Ohno, K. Tetrahedron Lett. 1965, 6, 3969.

[8] a) Kreis, M.; Palmelund, A.; Bunch, L.; Madsen, R. Adv. Synth. Catal. 2006, 348, 2148. b) Iwai, T.; Fujihara, T.; Tsuji, Y. Chem. Commun. 2008, 6215. c) Guo, X.; Wang, J.; Li, C.-L. J. Am. Chem. Soc. 2009, 131, 15092. d) Varela, J. A.; González-Rodriguez, C.; Rubín, S. G.; Castedo, L.; Saá, C. J. Am. Chem. Soc. 2006, 128, 9576. e) González-Rodriguez, C.; Varela, J. A.; Castedo, L.; Saá, C. J. Am. Chem. Soc. 2007, 129, 12916. f) Tang, R.-J.; He, Q.; Yang, L. Chem. Commun. 2015, 51, 5925.

[9] a) Huang, L.; Guo, H.; Pan, L.; Xie, C. Eur. J. Org. Chem. 2013, 6027. b) Park. A.; Park, K.; Kim, Y.; Lee, S. Org. Lett. 2011, 13, 944.

[10] a) Goossen, L. J.; Paetzold, J. Angew. Chem. Int. Ed. 2004, 43, 1095. b) Muto, K.; Yamaguchi, J.; Musaev, D.; Itami, K. Nature Commun. 2015, 6, 7508. c) Shuai, Q.; Yang, L.; Guo, X.; Basle, O.; Li, C.-J. J. Am. Chem. Soc. 2010, 132, 12212. d) LaBerge, N. A.; Love, J. A. Eur. J. Org. Chem. 2015, 5546.

[11] a) Stephan, M. S.; Teunissen, A. J. J. M.; Verzijl, G. K. M.; de Vries, J. G. Angew. Chem. Int. Ed. 1998, 37, 662. b) O'Brien, E. M.; Bercot, E. A.; Rovis, T. J. Am. Chem. Soc. 2003, 125, 10498. c) Matsuda, T.; Suzuki, K. RSC Advances, 2014, 4, 37138.

[12] a) Zhou, X.; Zafar, I.; Dong, G. Tetrahedron 2015, 71, 4478. b) Xu, T.; Savage, N.; Dong, G. Angew. Chem. Int. Ed. 2014, 53, 1891.

[13] Fujiwara, K.; Kurahashi, T.; Matsubara, S. Org. Lett. 2010, 12, 4548.

[14] Havlik, S. E.; Simmons, J. M.; Winton, V. J.; Johnson, J. B. J. Org. Chem. 2011, 76, 3588.

[15] Bilyard, K. G.; Garratt, P. J.; Hunter, R.; Lete, E. J. Org. Chem. 1982, 47, 4731.

[16] Ni-CO bond strengths have been estimated to be anywhere from 28.3 to $47.1 \mathrm{kcal} / \mathrm{mol}$; see: Sunderlin, L. S.; Wang, D.; Squires, R. R. J. Am. Chem. Soc. 1992, 114, 2788.

[17] Ziegler, T.; Tschinke, V.; Ursenbach, C. J. Am. Chem. Soc. 1987, 109, 4825.

[18] Li, J.; Schreckenbach, G.; Ziegler, T. J. Am. Chem. Soc. 1995, 117, 486.

[19] Tolman, C. A. Chem. Rev. 1977, 77, 313.

[20] Wong, K.-T.; Chen, R.-T.; Fang, F.-C.; Wu, C.-C.; Lin, Y.-T. Org. Lett. 2005, 7, 1979.

[21] Dennis, J. M.; Calyore, C. M.; Sjoholm, J. S.; Lutz, J. P.; Gair, J. J.; Johnson, J. B. Synlett 2013, 24, 2567.

[22] Bour, J. R.; Green, J. C.; Winton, V. J.; Johnson, J. B. J. Org. Chem. 2013, 78, 1665.

[23] Clot, E.; Eisenstein, O.; Jasim, N.; MacGregor, S. A.; McGrady, J. E.; Perutz, R. N. Acc. Chem. Res. 2011, 44, 333.

[24] a) Ryang, M.; Kwang-Myeong, S.; Sawa, Y.; Tsutsumi, S. J. Organomet. Chem. 1966, 5, 305. b) Laing, L.-C.; Hung, Y.-T.; Huang, Y.-L.; Chien, P.-S.; Lee, P.-Y.; Chen, W.-C. Oragnometallics 2012, 31, 700. 